\title{
COMUNICAÇ̃̃OCIENTÍFICA
}

\section{ENRAIZAMENTO DE ESTACAS SEMILENHOSAS DE MIRTILO SOB O EFEITO DE DIFERENTES CONCENTRAÇÕES DE ÁCIDO INDOLBUTÍRICO ${ }^{1}$}

\author{
DORALICE LOBATO DE OLIVEIRAFISCHER ${ }^{2}$, JOSÉ CARLOS FACHINELLO ${ }^{3}$, LUÍS EDUARDO CORRÊAANTUNES $^{4}$, \\ CARI REJANE FISS TIMM ${ }^{5}$, CLEVISON LUIZ GIACOBBO ${ }^{6}$
}

RESUMO - Dentre os métodos de multiplicação, o mirtilo pode ser propagado por sementes, rebentos, micropropagação e estaquia. Comercialmente, a propagação por meio de estaca é o método mais utilizado, proporcionando resultados diversos de acordo com a cultivar. Objetivou-se, com este trabalho, avaliar o efeito do ácido indolbutírico (AIB) no enraizamento de estacas semilenhosas de mirtilo das cultivares Delite e Bluebelle, coletadas em dezembro/2005. O material utilizado, oriundo de plantas irrigadas, foi segmento de ramos principais, com quatro gemas e diâmetro médio de $6 \mathrm{~mm}$, contendo duas folhas na extremidade superior, cortadas pela metade. Após o preparo, as estacas foram tratadas com AIB, nas concentrações de $0 ; 1.000 ; 2.000$ e $4.000 \mathrm{mg}$. $\mathrm{L}^{-1}$, sendo colocadas para enraizar em areia de granulometria grossa lavada, sob irrigação intermitente por microaspersão. O delineamento experimental utilizado foi em blocos ao acaso, com quatro repetições e dez estacas por parcela. Para a cultivar Bluebelle, o uso de AIB na concentração de $1.000 \mathrm{mg} . \mathrm{L}^{-1}$ propiciou, aos 120 dias após a instalação do experimento, maior número e comprimento de raízes, número e comprimento de brotações e enraizamento de 37,5\%. A cultivar Delite apresentou maior facilidade de emissão de raízes e brotações, independentemente do uso de AIB, com percentual de estacas enraizadas superior a 82,5\%.

Termos para indexação: propagação, estaquia, fitorregulador, Delite, Bluebelle.

\section{ROOTING OF SEMI-HARDWOOD CUTTINGS OF BLUEBERRY UNDER DIFFERENT INDOLEBUTYRIC ACID CONCENTRATIONS}

\begin{abstract}
Blueberries can be propagated by a variety of methods such as seeds, suckers, micropropagation and cuttings. Commercially, most propagation is done by cutting, providing different results depending on the cultivar. Thus, the objective of this research was to evaluate the indolebutyric acid (IBA) effect on rooting of semi-hardwood cuttings of blueberry cultivars Delite and Bluebelle collected on December/2005. Four-node segments with $6 \mathrm{~mm}$ approximately, containing 2 upper leaves cut in half were taken from main branches of irrigated plants. After preparation, the cuttings were treated with IBA at $0,1000,2000$ or $4000 \mathrm{mg} \mathrm{L}^{-1}$, and immediately inserted into rooting media (washed thick sand) under intermittent micro-sprinkler irrigation. The experimental design was a complete randomized block with four replications of ten cuttings. A hundred and twenty days after the experiment installation, Bluebelle provided large number and length of both roots and shoots, and had a rooting percent of $37.5 \%$, whether applying IBA at $1000 \mathrm{mg} \mathrm{L}^{-1}$. The cultivar Delite showed high facility to emit roots and shoots, regardless to IBA presence, showing more than $82.5 \%$ of rooted cuttings.
\end{abstract}

Index terms: propagation, cutting, phytoregulator. Delite and Bluebelle.

O mirtilo é uma espécie de importância econômica em vários países na América do Sul, como Chile, Argentina e, recentemente, Uruguai (Monteiro, 2004). Embora ainda pouco conhecida no Brasil, vem tornando-se uma boa alternativa para os produtores de algumas regiões do Sul e Sudeste, por ser uma fruta muito apreciada não somente pelo seu sabor exótico, como também pelos poderes medicinais e alto valor econômico (Antunes \& Madail, 2005). A produção insuficiente de mudas, decorrente das dificuldades técnicas de propagação, é um dos fatores limitantes à expansão da cultura (Hoffmann, 1994).
A propagação do mirtilo pode ser realizada por sementes, enxertia e estaquia. Dos meios disponíveis para se propagar mirtilo, a estaquia é a mais utilizada (Antunes et al., 2004). A propagação vegetativa por estacas enraizadas, além de reduzir a fase juvenil da planta, antecipando a produção, permite a obtenção de plantas uniformes, com características idênticas às da planta-mãe (Fachinello et al., 2005).

No sistema tradicional de produção de mudas por estaquia, tem sido recomendada a utilização de estacas de $10 \mathrm{a}$ $15 \mathrm{~cm}$ de comprimento, mantendo-se de duas a três folhas

\footnotetext{
'(Trabalho 121-07). Recebido em: 14-05-2007. Aceito para publicação em: 09-11-2007.

${ }^{2}$ Eng. Agra . Mestre em Agronomia pelo PPGA - Fruticultura de Clima Temperado - FAEM/UFPel. - Frutplan Mudas Ltda - Cx. P. 623 - $96001-970$ Pelotas - RS - doralicefischer@yahoo.com.br.

${ }^{3}$ Eng. Agro. Dr. Prof. Titular, Bolsista do CNPq - Departamento de Fitotecnia - FAEM/UFPel-- Cx. P. 354 - 96010-900 - sala 613 - Pelotas - RS jfachi@ufpel.tche.br.

${ }^{4}$ Eng. Agr ${ }^{\circ}$. Dr. Pesquisador, Bolsista do CNPq.- Embrapa Clima Temperado - Cx. P. 403 - 96001-970. - CPACT - Pelotas - RS. antunes@cpact.embrapa.br. ${ }^{5}$ Eng. Agr ${ }^{\mathrm{a}}$ - Colônia Osório, 96000000 - Pelotas - RS -fcari@yahoo.com.br.

${ }^{6}$ Eng Agr ${ }^{\circ}$. Dr. Prof. Adj. Agronomia, Universidade Federal do Pampa - UNIPAMPA, Campus de Itaqui, 97650-000, Itaqui - RS - giacobboc@unipampa.edu.br.
} 
superiores e eliminando-se as demais (Antunes et al., 2004). Para estacas semilenhosas, em geral, essas folhas podem ser cortadas ao meio, como forma de facilitar o manejo e evitar a perda de água (Fachinello et al., 1994).

A propagação comercial de mudas por estaquia é dependente da capacidade de enraizamento de cada espécie. As respostas à estaquia, dentro de uma mesma espécie, podem diferir entre as cultivares. O controle do desenvolvimento de raízes adventícias é influenciado por fitorreguladores, apresentando uma concentração ótima que pode variar entre espécies, populações ou clones, algumas promovendo e outras inibindo o processo de enraizamento (Costa \& Costa, 2003).

Segundo Kämpf (2000), para melhorar o processo de enraizamento, são empregados, comumente, o AIB (ácido indolbutírico) e o ANA (ácido naftalenacético). A concentração para o método de aplicação, usando imersão rápida em solução concentrada, é de $1.000 \mathrm{mg} . \mathrm{L}^{-1}$ a $8.000 \mathrm{mg} . \mathrm{L}^{-1}$.

Visando a melhorar a qualidade das mudas e a obter um maior percentual de enraizamento do material proveniente de matrizeiros de mirtilo, testou-se o enraizamento de estacas semilenhosas, sob o efeito de diferentes concentrações de AIB.

$\mathrm{O}$ experimento foi conduzido em estufa agrícola na Frutplan Mudas Ltda., localizada na colônia Ramos, $3^{\circ}$ distrito de Pelotas-RS, no período de dezembro de 2005 a abril de 2006. Foram utilizadas estacas semilenhosas das cultivares Delite e Bluebelle, provenientes de ramos principais oriundos de plantasmatrizes irrigadas, com quatro anos de idade.

Os ramos foram coletados na primeira quinzena de dezembro, no período da manhã, e colocados em baldes com água. À tarde, foram segmentados em estacas com quatro gemas e diâmetro médio de $6 \mathrm{~mm}$, descartando-se a parte apical dos ramos. Após a segmentação, foram removidas as folhas da base das estacas, deixando-se na extremidade superior duas folhas cortadas pela metade.

Com o auxílio de um canivete, foram feitas duas lesões superficiais na base das estacas. Posteriormente, as bases das mesmas foram imersas por 15 segundos em solução de AIB, nas concentrações de $0 ; 1.000 ; 2.000$ e 4.000 mg. $L^{-1}$, e colocadas para enraizar em caixas plásticas de $60 \times 40 \mathrm{~cm}$, com $15 \mathrm{~cm}$ de altura, contendo pedra brita $\mathrm{n}^{\circ} 2$ no fundo, para facilitar a drenagem, e areia de granulometria grossa como substrato.

O AIB foi dissolvido em álcool etilíco, na proporção de $40 \%$, e o restante do volume completado com água destilada. Como testemunha, foi utilizada apenas água destilada e álcool, na proporção de $40 \%$ do volume total da solução.

Após o plantio, as estacas foram regadas com uma solução fungicida Captan 500 PM (3 g.L $L^{-1}$ de água), sendo esse mesmo tratamento, repetido quinzenalmente na forma de pulverização.

O material propagativo foi mantido em ambiente protegido, sob sistema automático de irrigação intermitente por microaspersão, de forma a manter a umidade relativa próxima a $90 \%$, evitando a desidratação das estacas. O pH da água utilizada para irrigação foi corrigido para aproximadamente 5,0 com Quimifol P $30^{\circledR}$, conforme recomendação de Freire (2004) e Campos et al. (2005).
O delineamento experimental utilizado foi em blocos inteiramente casualizados, com duas cultivares (Delite e Bluebelle) e quatro concentrações de $\operatorname{AIB}\left(0 ; 1.000 ; 2.000\right.$ e 4.000 mg.L $\left.\mathrm{L}^{-1}\right)$, com quatro repetições e dez estacas por parcela.

Aos 120 dias, foram avaliados a porcentagem de estacas enraizadas, número médio de raízes por estaca, comprimento da maior raiz, número de brotações e comprimento da maior brotação.

Os dados foram submetidos à análise da variância pelo teste $\mathrm{F}$ e, quando significativos, submetidos à comparação entre médias, pelo teste de Duncan, a 5\% de significância. Os dados expressos em porcentagem (enraizamento) foram transformados em arco-seno da raiz de $\mathrm{x} / 100$. O programa estatístico utilizado foi oWinStat, versão 2.0 (Machado \& Conceição, 2003).

Em todas as variáveis analisadas, a cultivar Delite foi significativamente superior à cultivar Bluebelle (Tabela 1). As cultivares apresentaram comportamento diferenciado quanto à ação do fitorregulador em relação à formação, quantidade e tamanho das raízes e brotações. O percentual médio de enraizamento foi de $88,1 \%$ para a cultivar Delite, independentemente da utilização de AIB e de $16,38 \%$ para a cultivar Bluebelle, apresentando melhor resultado (37,5\%) com $1.000 \mathrm{mg} . \mathrm{L}^{-1}$ (Tabela 1). O mirtilo, quando propagado por estaquia, possibilita obter-se um percentual médio de enraizamento próximo a $50 \%$, entretanto os resultados obtidos são variáveis conforme a espécie e a cultivar (França, 1991; Silva \& Fett, 2006).

O comportamento diferenciado entre as duas cultivares, em relação à porcentagem de enraizamento, deve ser atribuído às diferenças genéticas. O melhor desempenho da cultivar Delite pode ter sido determinado pela quantidade apropriada de auxinas endógenas presentes nos tecidos. $\mathrm{O}$ fato de não ter havido redução no enraizamento com o aumento das concentrações de AIB, pode ser um indicativo de que as concentrações utilizadas não causaram efeito fitotóxico para essa cultivar.

No entanto, a cultivar Bluebelle apresentou melhores resultados quando utilizado o AIB, possivelmente por não possuir um teor endógeno de auxina em quantidade suficiente.

A diferença de enraizamento entre cultivares dessa espécie também foi observada por Hoffmann et al. (1994), que, ao estudarem o enraizamento de estacas de duas cultivares de mirtilo, em diferentes substratos, observaram que à cultivar Powderblue apresentou maior capacidade de enraizamento em relação a cultivar Climax, com 54\% e 1,3\%, respectivamente.

Para a cultivar Delite, o emprego do AIB influenciou apenas no comprimento de brotações, onde se observou melhor resultado $(7 \mathrm{~cm})$ na concentração de $1.000 \mathrm{mg} . \mathrm{L}^{-1}$, diferindo apenas da concentração de $2.000 \mathrm{mg} \cdot \mathrm{L}^{-1}$. Nas concentrações onde as brotações se apresentaram mais desenvolvidas, possivelmente o AIB tenha favorecido a iniciação de raízes mais cedo, permitindo a absorção de nutrientes disponibilizados pelo Quimifol P $30^{\circledR}$, favorecendo, dessa forma, o crescimento das brotações.

Embora trabalhando com outra espécie, Costa \& Costa (2003) relatam que, na avaliação do efeito de AIB no enraizamento de algumas cultivares de goiabeira, também não foram verificadas diferenças significativas quanto à porcentagem de formação de raízes em relação às testemunhas (sem adição de AIB).

Para a cultivar Bluebelle, o emprego de $1.000 \mathrm{mg} \mathrm{L}^{-1} \mathrm{de}$ 
AIB proporcionou resultados superiores em todas as variáveis analisadas (Tabela 1), em comparação com as demais concentrações. No entanto, o comprimento da maior raiz e o número de brotações por estacas não diferiu da testemunha.

Esses resultados são justificáveis, pois a aplicação de auxinas pode produzir efeito estimulante ao enraizamento até determinadas concentrações, a partir das quais passa a ser inibitório. Essa inibição é variável em raízes, caules e gemas, portanto a resposta à aplicação de auxinas depende da natureza do tecido, da espécie e da concentração da substância presente (Alvarenga \& Carvalho, 1983).
Possivelmente, o uso do AIB tenha favorecido a emissão de um maior número de raízes e, como conseqüência, o crescimento das brotações. As estacas com maior número de raízes assimilaram os nutrientes colocados à disposição com o uso do Quimifol P $30^{\circledR}$, utilizado na correção do pH.

De acordo com os resultados obtidos, pode-se concluir que a cultivar Bluebelle apresenta baixa capacidade de emissão de raízes e brotações a partir de estacas semilenhosas; a cultivar Delite apresenta facilidade de emissão de raízes e brotações independentemente do uso de AIB, com percentual de enraizamento superior a $82,5 \%$.

TABELA 1 - Enraizamento, número e comprimento da maior raiz, número e comprimento da maior brotação em estacas de mirtilo das cultivares Delite e Bluebelle. FAEM/UFPel, Pelotas-RS, 2007.

\begin{tabular}{|c|c|c|c|c|c|c|c|c|c|c|c|c|c|c|c|}
\hline \multirow[t]{2}{*}{$\begin{array}{c}\text { AIB } \\
\left(\mathrm{mg} \cdot \mathrm{L}^{-1}\right)\end{array}$} & \multicolumn{3}{|c|}{ Enraizamento (\%) } & \multicolumn{3}{|c|}{$\begin{array}{c}\text { Número de raízes } \\
\text { por estaca }\end{array}$} & \multicolumn{3}{|c|}{$\begin{array}{l}\text { Comprimento da maior } \\
\text { raiz }(\mathrm{cm})\end{array}$} & \multicolumn{3}{|c|}{$\begin{array}{c}\text { Número de brotações } \\
\text { por estaca }\end{array}$} & \multicolumn{3}{|c|}{$\begin{array}{c}\text { Comprimento da } \\
\text { maior brotação }(\mathrm{cm})\end{array}$} \\
\hline & Delite & Bluebelle & Média & Delite & Bluebelle & Média & Delite & Bluebelle & Média & Delite & Bluebelle & Média & Delite & Bluebelle & Média \\
\hline 0 & $82,5 \mathrm{aA}$ & $10,5 \mathrm{bB}$ & $46,3 \mathrm{a}$ & $11,4 \mathrm{aA}$ & $0,3 \mathrm{bB}$ & $5,9 \mathrm{a}$ & $7,3 \mathrm{aA}$ & $0,5 \mathrm{abB}$ & $4,0 \mathrm{a}$ & $1,3 \mathrm{aA}$ & $0,1 \mathrm{abB}$ & $0,7 a b$ & $5,5 \mathrm{abA}$ & $0,3 \mathrm{bB}$ & $2,9 \mathrm{~b}$ \\
\hline 1000 & $90,0 \mathrm{aA}$ & $37,5 \mathrm{aB}$ & $63,8 \mathrm{a}$ & $13,0 \mathrm{aA}$ & $2,9 \mathrm{aB}$ & $8,0 \mathrm{a}$ & $7,7 \mathrm{aA}$ & $1,8 \mathrm{aB}$ & $4,8 \mathrm{a}$ & $1,3 \mathrm{aA}$ & $0,3 \mathrm{aB}$ & $0,8 \mathrm{a}$ & 7,0 aA & $1,3 \mathrm{aB}$ & $4,2 \mathrm{a}$ \\
\hline 2000 & $95,0 \mathrm{aA}$ & $7,5 \mathrm{bB}$ & $51,3 \mathrm{a}$ & $14,3 \mathrm{aA}$ & $0,2 \mathrm{bB}$ & $7,3 \mathrm{a}$ & $8,7 \mathrm{aA}$ & $0,2 \mathrm{bB}$ & $4,4 \mathrm{a}$ & $1,1 \mathrm{aA}$ & $0,1 \mathrm{bB}$ & $0,5 \mathrm{~b}$ & $4,8 \mathrm{bA}$ & $0,1 \mathrm{bB}$ & $2,4 \mathrm{~b}$ \\
\hline 4000 & $85,0 \mathrm{aA}$ & $10,0 \mathrm{bB}$ & $47,5 \mathrm{a}$ & $13,3 \mathrm{aA}$ & $0,1 \mathrm{bB}$ & $6,7 \mathrm{a}$ & $7,8 \mathrm{aA}$ & $0,1 \mathrm{bB}$ & $4,0 \mathrm{a}$ & $1,1 \mathrm{aA}$ & $0,1 \mathrm{bB}$ & $0,6 \mathrm{~b}$ & $5,9 \mathrm{abA}$ & $0,1 \mathrm{bB}$ & $3,0 \mathrm{~b}$ \\
\hline Média & $88,1 \mathrm{~A}$ & $16,3 \mathrm{~B}$ & & $13,0 \mathrm{~A}$ & $0,9 \mathrm{~B}$ & & $7,9 \mathrm{~A}$ & $0,7 \mathrm{~B}$ & & $1,2 \mathrm{~A}$ & $0,1 \mathrm{~B}$ & & $5,8 \mathrm{~A}$ & $0,5 \mathrm{~B}$ & \\
\hline
\end{tabular}

Letras minúsculas distintas na coluna e maiúsculas na linha, para cada variável, diferem entre si, pelo teste de Duncan, a 5\% de significância.

\section{REFERÊNCIAS}

ALVARENGA, L.R., CARVALHO, V.D. Uso de substâncias promotoras de enraizamento de estacas frutíferas. Informe Agropecuário, Belo Horizonte, v. 9, n. 101, p.47-55, 1983.

ANTUNES, L.E.C.; GONÇALVES, E.D.; TREVISAN, R. Propagação. In: RASEIRA, M. do C.B; ANTUNES, L.E.C. A cultura do mirtilo. Pelotas: Embrapa Clima Temperado, 2004. p.29-36. (Documento, 121).

ANTUNES, L.E.C; MADAIL, J.C.M. Mirtilo: que negócio é esse? Jornal da Fruta, Lages, n.159, p.8, 2005.

CAMPOS, A.D; ANTUNES, L.E.C; RODRIGUES, A.C.; UENO, $B$. Enraizamento de estacas de mirtilo provenientes de ramos lenhosos. Pelotas: Embrapa Clima Temperado, 2005. 6 p. (Documento, 133).

COSTA, A. de F.S.; COSTA, A.N. da. Seleção de Plantas Matrizes de Goiaba, Produção de mudas e normas de condução de viveiros. In: __ Tecnologias para produção de goiaba. Vitória: Incaper, 2003.p.65-88.

FACHINELLO, J.C.; HOFFMANN, A.; NACHTIGAL, J.C., KERSTEN, E., FORTES, G.R. de L. Métodos de propagação vegetativa. In: FACHINELLO, J.C. et al. Propagação de plantas frutíferas de clima temperado. Pelotas: UFPel, 1994. p.41-147.

FACHINELLO, J.C; HOFFMANN, A.; NACHTGAL, J.C.; KERSTEN, E. Propagação vegetativa por estaquia. In:
FACHINELLO, J.C. et al. Propagação de plantas frutíferas. Brasília: Embrapa Informações Tecnológicas, 2005. p.69-109.

FRANÇA, S. Mirtilo: uma doce e rendosa novidade. Manchete Rural, Rio de Janeiro, n.46, p.32-34, 1991.

FREIRE, C.J. da S. Solos, nutrição e adubação para mirtilos. In: RASEIRA, M. do C.B; ANTUNES, L.E.C. A cultura do mirtilo. Pelotas: Embrapa Clima Temperado, 2004. p.43-54. (Documento, 121).

HOFFMANN, A. Propagação de mirtilo (Vaccinium ashei Reade) através de estacas. 1994. 84f. Dissertação (Mestrado em Agronomia)-Faculdade de Agronomia Eliseu Maciel, Universidade Federal de Pelotas, 1994.

KÄMPF, A.N. Propagação. In: . Produção comercial de plantas ornamentais. Guaíba: Agropecuária, 2000. p.151-170.

MACHADO, A.A.; CONCEIÇÃO, A.R. Sistema de análise estatística para windows. WinStat. Versão 2.0. Pelotas:UFPel, 2003.

MONTEIRO, C. La expansión dela producción de arándanos en Uruguay y su relación el Hemisferio Sur. In: SIMPÓSIO NACIONAL DO MORANGO, 2., 2004, Pelotas. Anais... Pelotas: Clima Temperado. p.233-242.

SILVA, L.R; FETT, M.S. Variedades e plantio de mirtilo. In: RESPOSTA técnica produzida pelo Serviço Brasileiro de Respostas Técnicas/SBRT. Disponível em: <http:// www.sbrt.ibict.br>. Acesso em: 10 jan. 2006. 